\title{
EFEKTIVITAS KINERJA IT SUPPORT MENGGUNAKAN FUNGSI SERVICE DESK SEBAGAI SINGLE POINT OF CONTACT (SPOC): STUDI KASUS PT XYZ
}

\author{
Rachmat Destriana \\ Program Studi Informatika \\ Fakultas Teknik Universitas Muhammadiyah Tangerang \\ Jl. Perintis Kemerdekaan 1/33 Cikokol Kota Tangerang \\ rachmat.destriana@gmail.com
}

\begin{abstract}
Service desk is Single Point Of Contact (SPOC) for every problem in every organization that has implemented IT-IL (Information Technology Infrastructure Library.) As SPOC is the spearhead that connects between customer and organization to improve service in company IT Support PT XYZ has run Service desk function, the problem is: is there any influence of success factor servicedesk to servicedesk performance process in it support? The problems contained in the question above are the object of research, which is expected to produce the desired answer, by conducting the research, using the primary data of the sample. Primary data is taken from field survey that is spread questioner to the selected sample. The data obtained will be used for the purposes of multiple regression analysis process, as well as to test the hypothesis of the influence of success factors servicedesk on the performance of servicedesk in it support. The result of the test and analysis is expected to give improvement in support in daily operaional using service desk function.
\end{abstract}

Keywords: Service desk, IT Support, Service desk success factor

\section{PENDAHULUAN}

Pada umumnya didalam suatu perusahaan memiliki unit atau divisi dalam menangani keluhan user mengenai masalah di area IT. Adakalanya ketersediaan infrastruktur IT belum dapat dimaksimalkan, bahkan kesesuaian infrastruktur dengan kepentingan bisnis belum selaras yang dapat berakibat pada tingkat efisien dan efektivitas sistem IT tidak optimal. Salah satu sarana yang dapat digunakan adalah SERVICE DESK, sarana ini dapat digunakan sebagai best practice dalam menjalankan proses IT dengan kepentingan bisnis bank. Berkaitan dengan paparan sebelumnya, maka adalah suatu hal yang menantang untuk mengukur dan menganalisis penerapan SERVICE DESK sebagai SPOC ( Single Point Of Contact) khususnya didalam divisi IT Support/BHOSD (Branch and Head Office Support Division ).
Salah satu perkembangan yang penting adalah semakin dibutuhkannya penggunaan alat pengolah data yang berfungsi untuk mencatat (logging) masalah yang timbul berkaitan dengan teknologi informasi dimana selanjutnya data-data yang telah dicatat tersebut selanjutnya diolah untuk melihat kecenderungan masalah yang terjadi pada teknologi informasi. Data tersebut sangat dibutuhkan terutama untuk kepentingan manajerial dalam suatu lembaga atau perusahaan teknologi informasi. Perusahaan-perusahaan yang ingin mengembangkan usaha dan mencapai sukses harus mengikuti era informasi dengan menggunakan alat pendukung pengolah data yang sangat kompeten dan dapat diandalkan serta sesuai dengan standar internasional. Dengan adanya tools/software yang berfungsi 
untuk me-manage semua masalah teknologi informasi yang terjadi, maka semua masalah yang terjadi dalam suatu perusahaan ataupun lembaga teknologi informasi dapat dikategorisasikan, dalam hal ini masalahmasalah yang dianggap penting dan sifatnya kritikal karena hal ini dapat mendukung keberhasilan suatu perusahaan dalam mencapai tujuannya.

\section{A. Identifikasi Masalah}

Berdasarkan pada latar belakang yang ada, studi ini mengidentifikasikan permasalahan sebagai berikut :

1. Bagaimana meningkatkan efktifitas kinerja Organisasi IT Support menggunakan faktor fungsi service desk.

2. Tidak maksimalnya kinerja IT support dalam menggunakan layanan service desk

3. Karena tidak berjalan maksimal fungsi service desk, sehingga keluhan atau pelaporan insiden lebih ke personal staf TI (IT support) dan penanganan insiden sering terabaikan

\section{B. Batasan Masalah}

Dalam hal ini penulis membatasi pada faktorfaktor pendukung suksesnya fungsi service desk terhadap IT support. Dimana efektivitas kinerja IT support masih terlihat kurang maksimal dalam operasional sehari-hari.

\section{Rumusan Masalah}

1. Faktor-faktor fungsi service desk apa saja yang berpengaruh terhadap proses kinerja dalam IT support?

2. Sejauh mana efektifitas kinerja IT support dipengaruhi dari faktor kesuksesan servicedesk, apakah signifikan atau tidak?

\section{TINJAUAN PUSTAKA}

\section{A. Pengertian IT-IL}

Menurut Cartlidge (2007), Information

Technology Infrastructure Library (IT-IL) adalah sebuah kerangka kerja atau konsep yang menggambarkan praktek terbaik dalam manajemen layanan teknologi informasi (TI). IT-IL menyediakan sebuah kerangka kerja untuk pengelolaan IT dan berfokus pada pengembangan dan pengukuran yang terus menerus terhadap kualitas dari layanan IT yang diberikan baik terhadap bisnis atau pelanggan. Fokus dari IT-IL sendiri ialah memberikan kontribusi dan keuntungan dalam menjalankan teknik-teknik dan proses-proses pada organisasi.

Menurut Addy (2007), IT-IL merupakan kumpulan dari petunjuk-petunjuk yang dikembangkan United Kingdom's Office of Government Commerce (OGC). Petunjukpetunjuk ini, yang menggambarkan prosesproses yang terintegrasi, yang menyediakan pendekatan praktek terbaik untuk mengelola layanan IT.

\section{B. Sejarah IT-IL}

Menurut Addy (2007), IT-IL pertama kali muncul pada akhir tahun 80an. Central Computer and Telecommunication Agency (CCTA) yang merupakan bagian dari departemen pemerintahan Inggris, dengan biaya IT sebesar 9 miliar pound, mendapatkan tekanan besar untuk dapat mengurangi biaya tersebut secara signifikan. CCTA memutuskan efisiensi besar merupakan salah satu cara potensial untuk mengurangi biaya tersebut. Akhirnya mereka menciptakan sebuah linkungan yang berfokus pada proses dan efisiensi untuk pengembangan sebuah kerangka kerja yang saat ini dikenal sebagai IT-IL.

Pada tahun 90an banyak perusahaan besar dan agen pemerintahan di Eropa mulai mengadopsi kerangka kerja IT-IL ini sebagai dasar dalam operasional IT. IT-IL mulai menyebar secara luas dan dengan cepat menjadi standar de facto untuk manajemen layanan IT.

Pada tahun 2001, kerangka kerja IT-IL versi 2 diperkenalkan.

Revisi baru ini telah diperbarui dengan definisi dan terminology yang lebih

modern terutama dalam pengembangan Service Delivery dan Service Support yang significant sehingga menjadi ringkas dan dapat digunakan.

\section{Tujuan IT-IL}

Tujuan IT-IL adalah untuk menyediakan petunjuk untuk praktek terbaik dalam 
manajemen layanan teknologi informasi. Ini mencakup pilihan yang dapat diapdopsi dan

diadaptasi oleh organisasi berdasarkan kebutuhan bisnisnya, keadaan, dan kedewasaan dari penyedia layanan ([BMCSoftware 2006],98).

\section{Keuntungan IT-IL}

Menurut Cartlidge (2007), beberapa keuntungan dari IT-IL, antara lain:

1. Meningkatkan kepuasan user dan pelanggan terhadap layanan IT.

2. Memperbaiki ketersediaan layanan, yang berpengaruh secara langsung dalam meningkatkan keuntungan dan pendapatan bisnis.

3. Menghemat keuangan, dari pengurangan kerja, kehilangan waktu. Memperbaiki manajemen sumber daya dan kegunaan. Memperbaiki pembuatan keputusan dan mengoptimalkan resiko. Memperbaiki waktu terhadap pasar untuk produk baru dan layanan.

\section{E. Konsep IT-IL}

IT-IL merupakan metodologi yang memberikan panduan best practice bagi IT

Service Management dalam membantu menghubungkan IT dengan kebutuhan pelayanan bisnis dan juga sebaliknya.

IT-IL memberikan pengaruh kepada manajemen termasuk di dalamnya manajemen orang dan proses, efektifitas teknologi, serta efisiensi dan ekonomis dalam memberikan pelayanan bisnis dengan service level yang telah disetujui bersama (antara IT dengan bisnis).

Keuntungan yang diperoleh dari IT-IL adalah bisnis yang lebih kompetitif diantaranya dengan meningkatnya kepuasan dan pelayanan nasabah, meningkatnya availability dan reliability dari pelayanan IT, meningkatnya roles dan responsibilities dari organisasi IT, menghubungkan IT dengan bisnis dan bisnis dengan IT.

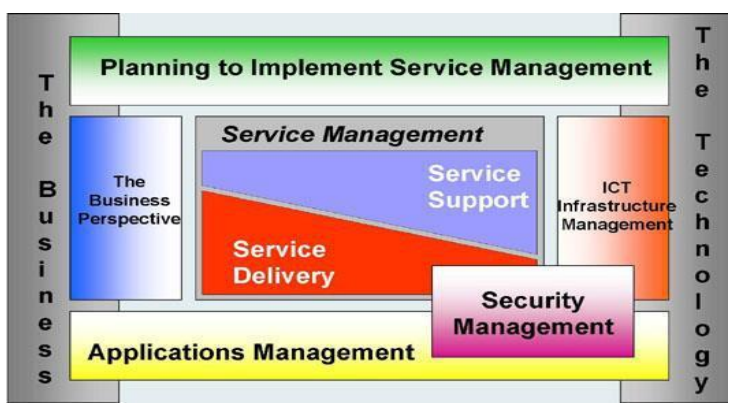

Gambar 1 Konsep IT-IL

IT-IL memiliki beberapa proses ([OGC 2003],90), diantaranya :

\section{Perpektif Bisnis (The Business \\ Perspective)}

Berfokus kepada pelurusan, pemahaman dan peningkatan IT yang berhubungan dengan kebutuhan bisnis sekarang dan yang akan datang.

\section{Manajemen infrastruktur ICT (ICT}

Infrastructure Management)

Manajemen infrastruktur Information and Communications Technology (ICT) berfokus pada kuantitas, kualitas, dan ketersediaan dari informasi yang berhubungan dengan infrastruktur. Meliputi manajemen pelayanan jaringan, manajemen operasi, manajemen dari lokal prosesor, instalasi komputer, dan manajemen sistem.

3. Perencanaan untuk menerapkann layanan manajemen (Planning to Implement Service Management)

Merupakan permintaan proses dan fungsi yang dibutuhkan untuk mengimplementasikan atau meningkatkan ketentuan pelayanan IT. Meliputi IT maturity, keuntungan dari manajemen pelayanan, peningkatan yang terus menerus yang pasti dihubungkan untuk mengimplementasikan proses IT-IL dan fungsi Service Desk.

4. Manajemen aplikas (Application

Management)

Lifecycledariaplikasi dan pengaruhnya terhadap implementasi, pengembangan, dukungan dan pengiriman pelayanan ICT. Manajemen aplikasi meliputi perubahan bisnis, definisi permintaan, dan 
implementasi dari solusi untuk menemukan kebutuhan bisnis.

5. Manajemen kemanan (Security

Management)

Merupakan bagian dari manajemen IT.

6. Manajemen layanan IT (IT Service

Management)

Merupakan kumpulan dari tanggung jawab yang saling berbagi, ditambah dengan disiplin dan proses yang saling berhubungan yang memampukan perusahaan untuk menjamin, mengawasi, dan mengatur infrastruktur IT untuk memberikan kualitas dan efektifitas pelayanan agar dapat menghubungkan keperluan bisnis jangka pendek dan jangka panjang.

\section{F. IT Service Management}

Menurut Addy (2007), IT Service Management terdiri dari dua bagian penting yaitu Service Delivery dan Service Support. Dimana dalam keseluruhan IT Service Management terdapat sepuluh proses manajemen dan sebuah fungsi Service Desk.

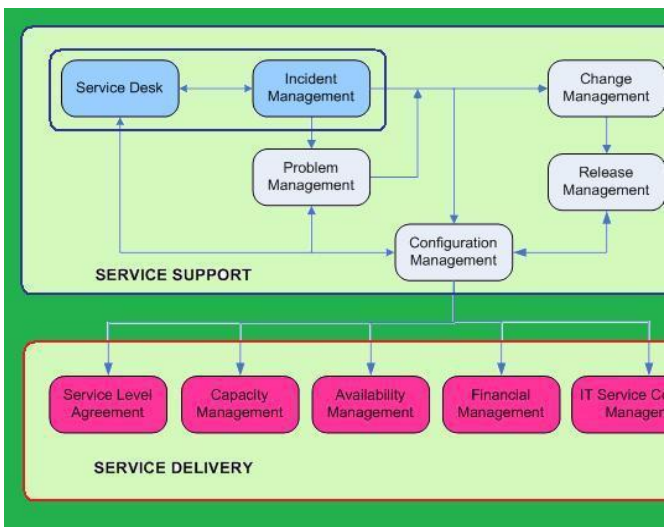

Gambar 2 IT Service

Management ([Addy 2007], 38)

Service Delivery merupakan proses tactical yang menyediakan kemampuan dalam memberikan dukungan yang memadai terhadap nasabah bisnis, lebih fokus kepada planning (rencana ke depan). Service Delivery meliputi proses Service Level Management, Capacity Management, Availability Management, Financial Management, IT Service Continuity Management.
Service Support merupakan fungsi dan proses operasional yang menjamin user untuk dapat mengakses pelayanan yang tepat demi mendukung fungsi dan pelayanan bisnis, lebih fokus kepada pelayanan operasional sehari-hari. Service Support meliputi proses Configuration Management, Incident Management, Problem Management,

Change Management, Release Management, serta fungsi Service Desk.

\section{G. Service Desk}

Service Desk sebagai Single Point Of Contact (SPOC)

Menurut BMCSoftware (2006), terdapat perbedaan antara penanganan masalah dari user, yaitu ;

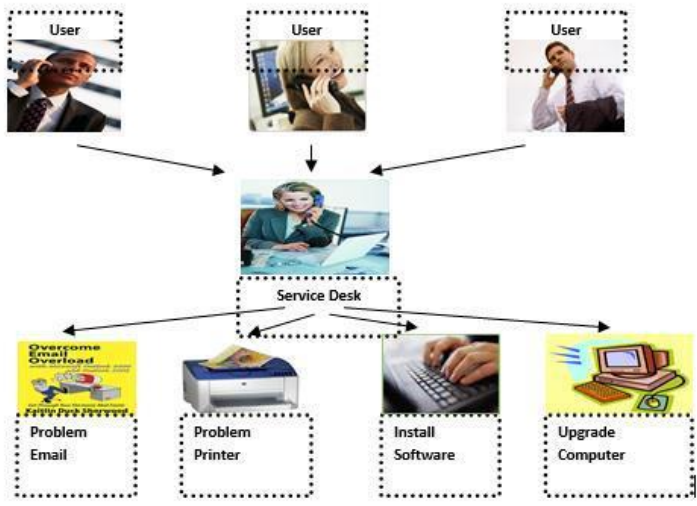

Gambar 3 SPOC ([BMCSoftware 2006],133)

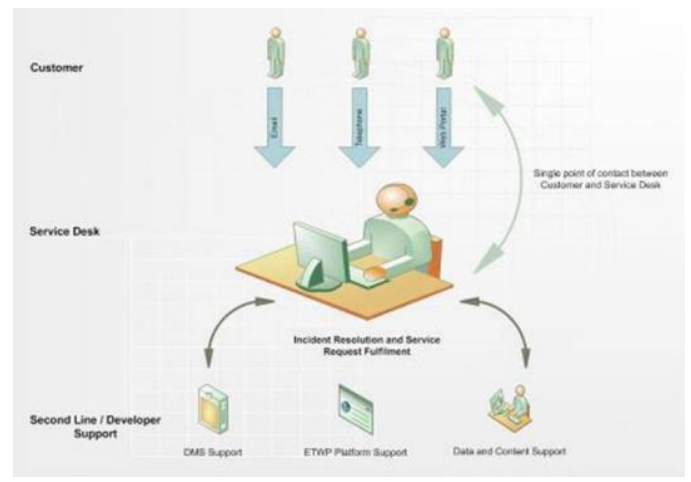

Gambar 4 SPOC ([BMCSoftware 2006],136)

Namun, dengan kehadiran IT Service Desk sebagai Single Point Of Contact (SPOC), pada saat user memiliki request ataupun incident, cukup IT Service Desk yang mereka hubungi, 
kemudian untuk berikutnya IT Service Desk yang akan meng-eskalasi. Dalam hal ini, IT Service Desk menjadi penghubung antara user dengan IT.

\section{METODE PENELITIAN}

\section{A. Metode Pengumpulan Data}

Pada penelitian ini, sampel yang diambil adalah populasi dari karyawan dalam hal ini adalah karyawan IT Support. Adapun teknik pengumpulan data dilakukan dengan cara pengumpulan data primer, yaitu dengan penyebaran kuesioner kepada responden yang telah terpilih.

\section{B. Target Populasi}

Populasi adalah jumlah keseluruhan dari obyek atau unit analisis yang karakteristiknya akan diteliti (Djarwanto, 1996, p102). Populasi yang telah ditentukan adalah populasi dari staff IT support yang memakai manfaat dari layanan service desk dan memiliki user id untuk menggunakan tools dariservice desk berupa Remedy - IT Service Management di Kantor Pusat Bank CIMB Niaga. Jumlah karyawan yang memiliki kriteria tersebut adalah 21 karyawan (IT support).

\section{Sampel dan Teknik Sampling}

Pengambilan sampel menggunakan sampel jenuh dimana pada penelitian ini dilakukan terhadap seluruh populasi karyawan tetap divisi IT Support sebanyak 21 karyawan.

Populasi dalam pengambilan sampel adalah bersifat unidentified (tidak teridentifikasi), dimana peneliti tidak melakukan identifikasi terlebih dahulu ketika pengambilan sampel.

Metode yang digunakan adalah nonprobability sampling merupakan proses pengambilan sampel yang mana probabilitas pemilihan tiap sampling unit-nya tidak diketahui. Teknik ini sangat tergantung pada penilaian peneliti.

Jenis yang diambil dalam penelitian ini adalah Judmental Sampling, yaitu elemen populasi dipilih berdasarkan penilaian peneliti. Peneliti memilih elemen ini berdasarkan penilaiannya bahwa elemen-elemen tersebut mewakili populasi penelitian yang bias berpengaruh terhadap efektifitas kinerja di IT support.

\section{Instrumen Pengumpulan Data}

Dalam pengumpulan data penelitian ini menggunakan kuesioner sebagai instrumen pengumpulan data. Kuesioner akan berisikan pertanyaan-pertanyaan untuk dijawab oleh responden guna memperoleh informasi yang dibutuhkan dalam penelitian, kuesioner ini juga dimaksudkan untuk mendukung penelitian yang dilakukan memiliki validitas dan reabilitas yang tinggi. Untuk dapat memberikan jawaban yang menggambarkan situasi yang sebenarnya, maka kuesioner ini disusun secara jelas, tidak membingungkan dan bisa dipakai oleh semua responden agar dapat menghindari atau meminimalkan kemungkinan kesalahan pengertian oleh responden.

\section{E. Skala Pengukuran}

Skala pengukuran yang digunakan pada kuesioner ini adalah skala Likert (Sugiyono, 2007). Skala Likert menggunakan nilai intensitas $1-4$. Skala ini mengartikan tingkat kepercayaan responden dari setiap butir pertanyaan.

\section{F. Metode Pengolahan Data}

Pengolahan data hasil dari jawabab kuesioner diolah dengan menggunakan software Statistic Product and Service Solution (SPSS) 16. Melalui program SPSS kegiatan pengolahan data dapat dilakukan dengan mudah, tanpa harus melibatkan pemakai dalam persoalan rumus-rumus statistik di atas tidak akan terlihat secara langsung.

\section{ANALISIS DAN PEMBAHASAN}

A. Analisis Validitas dan Reliabilitas

1. Hasil analisis Uji Validitas dan Reliabilitas komitmen manajemen (X1) 
Tabel 1 Hasil Uji Validitas Variabel Komitmen Manajemen (X1)

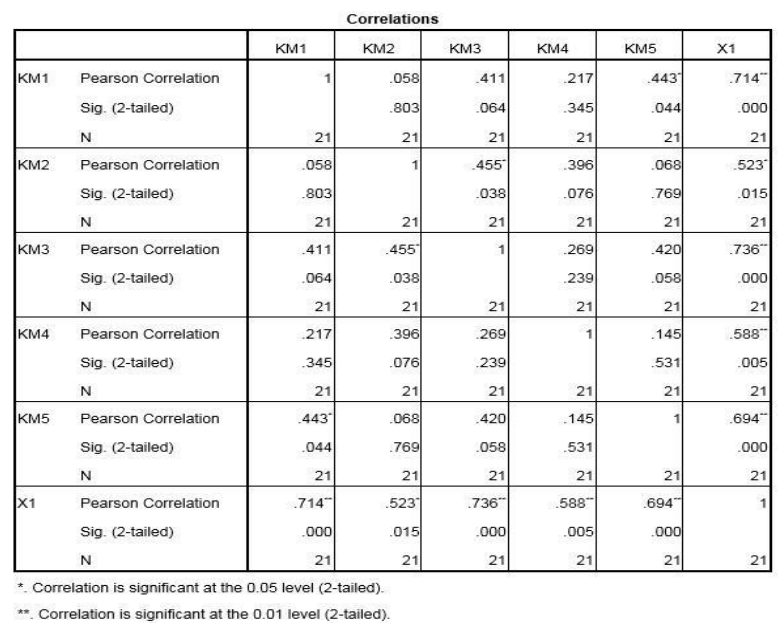

\section{Uji Reliabilitas}

\section{Dimana:}

$\mathrm{Y}=\mathrm{EK}=$ Efektivitas Kinerja

$\mathrm{X} 1=\mathrm{KM}=$ Variabel standardized Komitmen Manajemen

$\mathrm{X} 2=\mathrm{KB}=$ Variabel standardized Kebutuhan Bisnis

$\mathrm{X} 3=\mathrm{PP}=$ Variabel standardized Pemeliharaan dan Pelatihan

$\mathrm{X} 4=\mathrm{KP}=$ Variabe Statistics $\mathrm{X}$.hudahan Pengguna

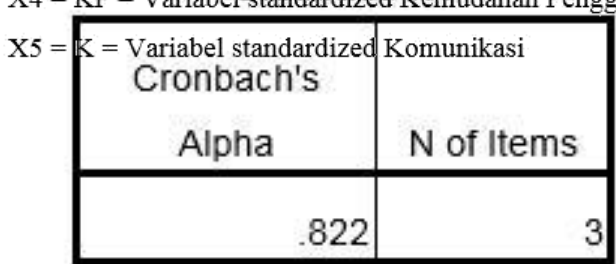

\section{B. Uji Asumsi Klasik}

Uji Normalitas Data

Tabel 2 Uji Normalitas

\section{One-Sample Kolmogorov-Smirnov Test}

\begin{tabular}{|ll|r|r|r|r|r|}
\hline & & \multicolumn{1}{c|}{ X1 } & \multicolumn{1}{c|}{ X2 } & \multicolumn{1}{c|}{ X3 } & \multicolumn{1}{c|}{ X4 } & \multicolumn{1}{c|}{ X5 } \\
\hline N & & 21 & 21 & 21 & 21 & 21 \\
Normal Parameters & Mean & 15.0476 & 12.1905 & 21.5238 & 11.6667 & 12.7619 \\
& Std. & & & & & \\
& Deviation & 2.35534 & 1.83355 & 2.67617 & 2.17562 & 2.02249 \\
Most Extreme & Absolute & .181 & .194 & .097 & .132 & .166 \\
Differences & Positive & .108 & .123 & .097 & .112 & .094 \\
& Negative & -.181 & -.194 & -.094 & -.132 & -.166 \\
& .829 & .891 & .446 & .606 & .760 \\
Kolmogorov-Smirnov Z & .498 & .406 & .989 & .856 & .610 \\
\hline Asymp. Sig. (2-tailed) & & & & & \\
\hline \multicolumn{2}{|l|}{ a. Test distribution is Normal. } & & & &
\end{tabular}

Dalam penelitian ini Uji Normalitas data dilakukan dengan menggunakan tool software SPSS versi 16 Uji normalitas adalah untuk melihat apakah nilai residual terdistribusi normal atau tidak dan salah satu syarat untuk olah data ke interval ([Gunawan Sudarmanto 2005], 104). Model regresi yang baik adalah memiliki nilai residual yang terdistribusi normal. Jadi uji normalitas bukan dilakukan pada masing-masing variabel tetapi pada nilai residualnya.

C. Analisis Regresi Ganda Variabel X1, X2, $X 3$, dan X4 terhadap $Y$ dan Koefesien

$\mathrm{Y}=\mathrm{a}+\mathrm{b} 1 \mathrm{X} 1+\mathrm{b} 2 \mathrm{X} 2+\mathrm{b} 3 \mathrm{X} 3+\mathrm{b} 4 \mathrm{X} 4+\mathrm{b} 5 \mathrm{X} 5$

$\mathrm{EK}=\mathrm{a}+\mathrm{b} 1 \mathrm{KM}+\mathrm{b} 2 \mathrm{~KB}+\mathrm{b} 3 \mathrm{PP}+\mathrm{b} 4 \mathrm{KP}+\mathrm{b} 5 \mathrm{~K}$

$\mathrm{EK}=-5.055+0,278 \mathrm{KM}+1,401 \mathrm{~KB}+0,110 \mathrm{PP}+0,572 \mathrm{KP}-0.031 \mathrm{~K}$ $\mathrm{R}^{2}=0,875$ Adjusted $\mathrm{R}^{2}=0,830 \mathrm{~F}=20,541$

\section{Regresi}

Berdasarkan tabel IV.7 telah ditemukan persamaan regresi ganda linier sebagai

berikut :

D. Interpretasi Regresi Ganda Variabel X1, X2, X3, dan X4 terhadap Y dan Koefesien Regresi.

$\mathrm{EK}=-5.055+0,278 \mathrm{KM}+1,401 \mathrm{~KB}+$

$0,110 \mathrm{PP}+0,572 \mathrm{KP}-0.031 \mathrm{~K}$

E. Koefesien Determinasi $\left(R^{2}\right)$

Tabel 3 Koefisien Determinasi $\left(\mathrm{R}^{2}\right)$

\begin{tabular}{|l|r|r|r|r|}
\hline Model & \multicolumn{1}{|c|}{ R } & R Square & $\begin{array}{c}\text { Adjusted R } \\
\text { Square }\end{array}$ & $\begin{array}{c}\text { Std. Error of the } \\
\text { Estimate }\end{array}$ \\
\hline 1 & $894 *$ & 873 & 830 & 1.76476 \\
\hline
\end{tabular}

\section{F. Pengujian Hipotesis}

1. Uji Simultan dengan F-Test.

Uji Simultan dengan F-Test dilakukan untuk mengetahui pengaruh bersama-sama variabel bebas yaitu komitmen manajemen (X1), 
kebutuhan bisnis dan it supprot (X2), pemeliharaan dan pelatihan (X3), Kemudahan pengguna (X4) komunikasi (X5) secara bersama-sama terhadap variabel terikat yang dalam hal ini Efektivitas kinerja IT support (Y). Hasil Ftest menunjukkan variabel bebas secara bersama-sama berpengaruh terhadap variable terikat jika :

$\lceil\quad$ Fhitung $>$ Ftabel atau nilai $p$-value pada kolom sig. < level of significant $(\alpha)$,

maka $\mathrm{H} 0$ ditolak dan Ha diterima.

Fhitung < Ftabel, atau nilai p-value pada kolom sig. > level of significant $(\alpha)$,

maka H0 diterima dan Ha ditolak $\square$

Dengan taraf signifikan : $\alpha=0,05$

$\ulcorner\quad \mathrm{F}$ tabel dihitung dengan cara df $1=\mathrm{k}-1$, dan df2 $=\mathrm{n}-\mathrm{k}$, dimana $\mathrm{n}$ adalah jumlah responden dan $\mathrm{k}$ adalah jumlah variabel terikat dan bebas.

df $1=\mathrm{k}-1,6-1=5$

df $2=21-6=15$

$\mathrm{F}$ table $=2.90$

Tabel 4 ANOVA

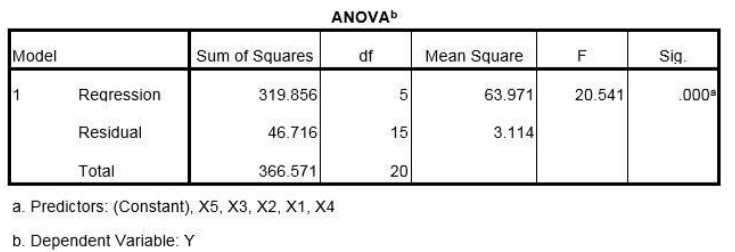

Berdasarkan output SPSS tersebut menunjukkan $p$-value $0,000<0,05$, artinya siginifikan, sedangkan $\mathrm{F}$ Hitung 20,541 > F tabel 2,90, artinya signifikan. Signifikan disini berarti Ha diterima dan Ho ditolak, artinya seluruh variabel bebas yaitu komitmen manajemen (X1), kebutuhan bisnis dan it supprot (X2), pemeliharaan dan pelatihan (X3), Kemudahan pengguna (X4) komunikasi (X5) secara bersama-sama berpengaruh signifikan terhadap variabel terikat yaitu pengambilan keputusan (PK).

\section{G. Implikasi Penelitian}

\section{Aspek Manajemen}

Dari hasil peneltian Efektivitas Kinerja IT support dapat lebih efektif dan dapat ditingkatkan dengan memperhatikan faktorfaktor yang berpengaruh terhadapnya, terutama faktor-faktor yang berasal dari fungsi service desk yang saat ini berjalan.

Faktor-faktor tersebut diantaranya adalah kebutuhan Bisnis dan Keperluan IT Support dan kemudahan Penggunaan, disamping faktorfaktor eksternal. kebutuhan Bisnis dan Keperluan IT Support dianggap sebagai faktor kunci yang paling menentukan dalam efektivitas Kinerja IT support, mengingat kebutuhan Bisnis dan Keperluan IT Support merupakan tujuan utama dari suatu perusahaan dan divisi IT support khususnya. Untuk itu Peningkatan kebutuhan Bisnis dan Keperluan IT Support sangatlah penting untuk diperhatikan. Hal ini bisa dibuktikan dari hasil penelitian ini, dimana kebutuhan Bisnis dan Keperluan IT Support memiliki nilai koefisien yang paling besar di dalam model persamaan.

\section{Aspek Sistem}

Service Desk merupakan kontak pertama pelaku bisnis atau user yang memanfaatkan Service, jika terjadi sesuatu dengan Service yang tidak mereka harapkan. Service Desk merupakan "pintu" komunikasi utama bagi end user jika membutuhkan bantuan. Selama service desk ini tidak berjalan maksimal sebagai fungsinya, sehingga keluhan atau pelaporan insiden lebih ke personal staf TI (IT support ) dan penanganan insiden sering terabaikan sehingga dirasa kurang mampu meningkatkan efektivitas kinerja IT support.

Dari hasil penelitian ini dapat diambil kesimpulan bahwa untuk memaksimalkan fungsi service desk maka salah satu factor dari fungsi service desk yang harus ditingkatkan adalah kemudahan penggunaan dari layanan service desk sendiri sehingga mampu meningkatkan kinerja IT support pada PT CIMB Niaga. 


\section{KESIMPULAN}

Dari hasil penelitian terhadap karyawan sebagai pengguna layanan service desk di PT.CIMBNiaga kantor pusat, yang dimulai dengan mengisi kuesioner pada bulan Januari 2010, kemudian dilanjutkan dengan tabulasi dan pengolahan data lalu dilanjutkan dengan uji statistik, diperoleh gambaran bahwa dari lima factor kesuksesan fungsi servicedesk hanya terdapat dua factor yang berpengaruh yaitu kebutuhan bisnis dan keperluan IT support serta kemudahan penggunaan sementara ketiga factor lainnya yang tidak berpengaruh terhadap kinerja IT support adalah komitmen manajemen, pemeliharaan dan pelatihan serta komunikasi.

Sehingga dapat diambil kesimpulan bahwa secara keseluruhan presentase keberhasilan faktor-faktor kesuksesan service desk didalam kontribusinya terhadap kinerja IT support hanya $40 \%$ saja atau faktor-faktor kesuksesan service desk didalam kontribusinya terhadap kinerja IT tidak Signifikan.

\section{REFERENSI}

[1] Ariastuti, Ayu , "Faktor-faktor Yang Menentukan Loyalitas Pelanggan Terhadap Merek Teh Botol Sosro di Kota Denpasar", Denpasar, 2005.

[2] Addy, Rob. "Effective IT Service Management: to ITIL and Beyond!, $1^{\text {st }}$ ed," Springer-Verlag Berlin Heidelberg., Germany, 2007.

[3] Gulo, W. "Metodelogi Penelitian", PT. Gramedia Widiasarana Indonesia, Jakarta, 2010

[4] BMCSoftware. "ITIL Foundation Concepts of IT Service management (ITSM).

[5] Office of Government Commerce (OGC)." The key to Managing ITServices - Service Support, $2^{\text {nd }}$ ed." The Satationery Office Norwich, 2003.

[6] Office of Government Commerce (OGC). "The Official Introduction to the ITIL Service Lifecycle, $1^{\text {st }}$ ed.", The Satationery Office Norwich, 2007.
[7] Santoso, Singgih, "Buku Latihan SPSS Statistik Parametrik", PT. Elex Media Komputindo Kelompok Gramedia, Jakarta, 2000.

[8] Santoso, Singgih. "Buku Latihan SPSS Statistik Non Parametrik”, PT. Elex Media Komputindo Kelompok Gramedia, Jakarta, 2001.

[9] R Sudarmanto, Gunawan, “ Buku Analisa Regresi Liner Ganda dengan SPSS”, PT. Graha Ilmu, Jakarta, 2005.

[10] Djarwanto. "Mengenal Beberapa Uji Statistik Dalam Penelitian, Edisi ke1, Liberty," Yogyakarta 1996.

[11] Sugiyono. " Metode Penelitian Bisnis". Alfabeta, Bandung, 2007. 